\title{
Language Disorders in Children with Unilateral Hearing Loss: A Systematic Review
}

\author{
Maria Renata José ${ }^{1}$ Maria Fernanda Capoani Garcia Mondelli ${ }^{2}$ Mariza Ribeiro Feniman ${ }^{2}$ \\ Simone Aparecida Lopes-Herrera ${ }^{2}$ \\ ${ }^{1}$ Bauru School of Dentistry, Universidade de São Paulo - USP, Bauru, SP, \\ Brazil \\ 2 Department of Speech-Language Pathology and Audiology, Bauru \\ School of Dentistry, Universidade de São Paulo - USP, Bauru, SP, Brazil \\ Int Arch Otorhinolaryngol 2014;18:198-203.
}

\begin{abstract}
Introduction Childhood is a critical period for language development and maturation of the central auditory system. Unilateral hearing loss (UHL) is considered a minimal impairment, and little is discussed regarding its impact on the development of language, communication, and school performance.

Objectives A bibliographical survey of scientific articles published from 2001 to 2011 was performed to verify which language disorders can occur in children with UHL and which tests were performed to identify them.

Data Synthesis Three databases were used: PubMed, Lilacs, and The Cochrane Library. As inclusion criteria, the articles should have samples of children with UHL, without other impairments, aged between 3 months and 12 years, and reference to language tests applied in this population. Out of 236 papers initially selected, only 5 met the inclusion criteria. In the articles studied, 12 tests were used for language assessment in children with $\mathrm{UHL}$, out of which 9 were directed toward expressive language, and 3 toward receptive language. Children with UHL demonstrated lower scores on receptive and expressive

Keywords

- hearing loss

- unilateral

- child

- language development

- language language tests when compared with children with normal hearing. However, they obtained better scores on expressive language tests than children with bilateral hearing loss. Conclusion The findings of this survey showed that only a small number of studies used language tests in children with UHL or addressed language alterations resulting from this type of impairment. Therefore we emphasize the importance of investments in new studies on this subject to provide better explanations related to language difficulties presented by children with UHL.
\end{abstract}

\section{Introduction}

Since the implementation of the public policy that makes universal newborn hearing screening (UNHS) compulsory, there has been a higher incidence of early diagnosed hearing loss. Among the impairment types, unilateral hearing loss (UHL) is commonly diagnosed in school-age children, at around 5 years of age. ${ }^{1,2}$ UHL identification in most children occurs initially (38\%) through school screening ${ }^{3}$ and secondarily through parental suspicion (16\%).

received

May 18, 2013

accepted

August 14, 2013
DOI http://dx.doi.org/

$10.1055 / \mathrm{s}-0033-1358580$. ISSN $1809-9777$.
UHL is considered a minimal impairment, as well as mild degrees of hearing loss, high-frequency hearing loss, and conductive hearing loss. However, even the term minimal is controversial, as it might imply that these losses are not important or seem of little consequence. ${ }^{4}$

Childhood is a critical period for language development and maturation of the central auditory system. Studies ${ }^{5-7}$ have shown that hearing loss, in one single ear, can cause a decline in word recognition. This phenomenon may be observed in children with moderate bilateral hearing loss who

Copyright $(2014$ by Thieme Publicações License terms Ltda, Rio de Janeiro, Brazil

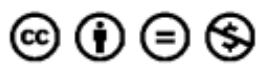


were monaurally aided and demonstrated a significant decline in word recognition performance in their unaided ears for at least 4 years. ${ }^{4}$ Health care professionals and teachers pay little attention to minimal hearing loss because they believe it can have very little influence in language and communication development and in school performance. ${ }^{8,9}$

Parents may not notice any hearing problems during the first year of life of their children who suffer from UHL, due to the superiority of the hearing stimulus reception in relation to noise. When the child starts crawling and/or walking, this difference may become evident due to the increasing distance of the sound stimuli and the interference of background noise. ${ }^{10}$ The fitting of a personal amplification devices at this stage could help the early development of listening skills and minimize any language difficulties that might occur due to the discrepancy of sound stimuli reception, generating an inadequate stimulation of the central auditory system ${ }^{11}$ and integration of auditory information.

Children with UHL are more likely to experience academic difficulties, have behavioral problems, be more distracted, have greater need for tutoring, 4,12 and show lower performances in oral language compared with their peers with normal hearing. ${ }^{2}$ Yoshinaga-Itano et $\mathrm{al}^{13}$ concluded that without early identification and intervention, about one third of the children with mild bilateral or UHL will present difficulties in different areas of communication.

An important discussion topic is how beneficial the use of hearing aids could be for children with UHL, because the ear with hearing within normal thresholds can compensate for the ear with a weaker hearing threshold, creating difficulties only for sound localization, and in the presence of environmental noise. However, even with this compensation, children with UHL usually have greater difficulties in understanding speech. ${ }^{14}$ Unlike bilateral hearing loss, there is no consensus of the benefit of the intervention and use of hearing aids in unilateral congenital conductive hearing loss. ${ }^{15}$

The American Academy of Audiology with its Pediatric Amplification Protocol ${ }^{16}$ states that children with mild hearing loss are considered candidates for amplification and/or use of individual frequency modulation (FM) systems. The decision of amplification in children with UHL is made by the family based on individual needs as well as audiological, developmental, communicative, and educational factors. ${ }^{10}$

Bilateral hearing loss, even fluctuating or mild, is enough to impair listening skills ${ }^{17}$ and has implications in language development. This occurs as a consequence of inadequate reception of sound stimuli, causing the child's central auditory system to receive inconsistent stimulation, which hinders the perception of environmental sounds. ${ }^{11}$

In UHL, speech difficulties are not yet a consensus, because studies ${ }^{18,19}$ have shown that children with this type of hearing loss reorganize their auditory cortex and may present similar development as their peers with normal hearing. Another bibliographical survey ${ }^{11}$ on the impact of otitis media in children's language pointed out that even those children with mild UHL may present compromised language acquisition.

The objective of this study was to determine, based on a survey of national and international recently published ar- ticles, which language disorders may occur in children with UHL and what types of tests were used to identify such disorders.

\section{Methods}

To perform the bibliographical survey, researchers previously defined the criteria for the inclusion and exclusion of national and international articles and the bibliographical research period. This systematic review of the UHL literature used the following inclusion criteria: articles should study samples of children, aged between 3 months and 12 years, with UHL without any other impairment, and articles should include results of language tests applied to evaluate language disorders in this population. Journal articles were excluded if the participants had any cognitive or intellectual language deficits associated with UHL. Articles that reported only the incidence of UHL unrelated to language development were also excluded from the study.

A bibliographical survey of scientific articles published over the past 10 years was performed (between the years of 2001 and 2011) using three different databases: PubMed (www.pubmed.gov), Lilacs, and the Cochrane Library (regional.bvsalud.org). To ensure that there were no publications on the same subject, we began searching in the Cochrane Library, and no studies addressing similar subjects were found.

The descriptors (DeCS/MeSH) used for searches in the databases were: (1) hearing loss, unilateral; (2) language; (3) child; (4) preschool; (5) vocabulary test; (6) language test; (7) language development; (8) child language; (9) language comprehension; (10) language comprehension test. In all databases, searches were performed using descriptors in English and using the simple search.

Twelve strategies were used three databases. Each strategy was a combination of three descriptors (DeCS/MeSH), separated manually by the operator AND. The 12 strategies obeyed the descriptors combination as follows: $1,2,3$ (strategy 1 ); 1 , 2, 4 (strategy 2); 1, 5, 3 (strategy 3); 1, 5, 4 (strategy 4); 1, 6, 4 (strategy 5); 1, 7, 3 (strategy 6); 1, 7, 4 (strategy 7); 1, 6, 3 (strategy 8); 1, 8, 6 (strategy 9); 1, 9, 3 (strategy 10); 1, 8, 5 (strategy 11); and 1, 8, 10 (strategy 12).

Initially, the selection was made by reading the title and abstract of each study found in the databases. All the articles that did not meet the inclusion criteria of this study, that were shown repeatedly in the same or another database, or that were not available in full by the databases of the university were excluded.

\section{Review of Literature}

The researchers collected 236 articles, out of which 226 studies were found in PubMed (95.8\%) and 10 articles in Cochrane $(4.2 \%)$. No study with the descriptors used was found in Lilacs.

The numbers of studies found in the three databases are shown in -Table 1, according to the 12 combinations of descriptors (DeCS/MeSH) described as data search strategies in the Methods section. 
Table 1 Number of articles found in each strategy in the different databases

\begin{tabular}{|l|l|l|l|}
\hline Strategy & PubMed & Lilacs & Cochrane \\
\hline 1 & 37 & 0 & 3 \\
\hline 2 & 24 & 0 & 0 \\
\hline 3 & 17 & 0 & 0 \\
\hline 4 & 17 & 0 & 0 \\
\hline 5 & 14 & 0 & 0 \\
\hline 6 & 26 & 0 & 3 \\
\hline 7 & 17 & 0 & 0 \\
\hline 8 & 20 & 0 & 2 \\
\hline 9 & 20 & 0 & 2 \\
\hline 10 & 1 & 0 & 0 \\
\hline 11 & 17 & 0 & 0 \\
\hline 12 & 16 & 0 & 0 \\
\hline Total & 226 & 0 & 10 \\
\hline
\end{tabular}

Note: Strategy 1 retrieved largest number of articles, totaling 37 articles containing the terms "hearing loss," "unilateral," "language," and "child," followed by strategy 6 , totaling 26 articles containing the terms "hearing loss," "unilateral," "language development," and "child."

The initial selection was made by reading the titles and abstracts. At this stage, all the articles that did not meet the inclusion criteria, articles that referred only to the unilateral adaptation of hearing aids or cochlear implants in children with bilateral hearing loss, or articles that used other tests unrelated to language assessment were excluded. Initially 14 studies were selected for the study.

Three systematic reviews were found, as well as one editorial and four articles that reported the incidence of UHL without associating it with language development, and another one in which magnetic resonance imaging was performed to verify the area of the brain activated through auditory stimulation. They were all excluded from the study. In the end, only five articles met the inclusion criteria, as shown in $\boldsymbol{- T}$ Table 2.

- Table 3 characterizes the participants in the studies of the selected articles, reporting the total sample size, and how many children had UHL. It also describes the type and degree of hearing loss only in children with UHL.

The samples of studies 1 and 2 ( - Table 2 ) were composed of groups of children with UHL, and these were compared with the group of children with normal hearing. However, study 5 comprised 55 children with UHL, 87 with normal hearing, and 144 with bilateral hearing loss. Study 4 compares the language test results in children with unilateral and bilateral conductive hearing loss, but did not specify the number of children with UHL. Only in study 3 , the sample was composed exclusively of children with UHL.

Regarding the devices used by the children, study 1 revealed that 22 children used an FM system, 4 of them used individual hearing aids, 3 used a contralateral routing of signals, and 3 others used a bone-anchored hearing aid
Table 2 Year of publication, authors, and country in which the study was performed, according to the analysis of selected articles

\begin{tabular}{|l|l|l|l|}
\hline Study & Year & Authors & Country \\
\hline $1^{10}$ & 2010 & $\begin{array}{l}\text { Lieu JEC, Tye-Murray N, } \\
\text { Karzon RK, Piccirillo JF }\end{array}$ & USA \\
\hline $2^{20}$ & 2009 & $\begin{array}{l}\text { Martínez-Cruz CF, } \\
\text { Poblano A, } \\
\text { Conde-Reyes MP }\end{array}$ & Mexico \\
\hline $3^{18}$ & 2007 & $\begin{array}{l}\text { Priwin C, Jönsson R, } \\
\text { Magnusson L, } \\
\text { Hultcrantz M, } \\
\text { Granström G }\end{array}$ & Sweden \\
\hline $4^{21}$ & 2002 & Paradise JL et al & USA \\
\hline $5^{22}$ & Borg et al & Sweden \\
\hline
\end{tabular}

(BAHA). Study 3 showed that 4 participants used a BAHA, but did not mention if they were children or adults. Study 4 used the ventilation tube as an intervention in children under 3 years of age. In study 5 , the children used personal hearing aids, but it did not mention how many of them used amplification devices. Study 2 did not report the use of devices among its participants.

- Table 4 shows the tests used for language assessment and other tests used to complement that same assessment of the children studied.

It can be observed that out of the 12 tests mentioned in the surveyed articles, which were done for language assessment, 9 of them were directed toward expressive language (75\%) and $3(25 \%)$ assessed receptive language. Studies 1, 2, and 4 assessed both receptive and expressive language mastery. None of the tests were repeated in more than one study. Other tests were conducted to complement language assessment, such as cognitive and discrimination tests, as well as a test for auditory processing disorders.

By evaluating the results of the language tests used in each study, it is possible to observe that in study 1 children with hearing loss had a lower performance on both tests that assessed receptive and expressive languages when compared with children without hearing loss, but no difference was found in relation to the cognitive aspects. In study 2 , children with UHL have shown lower intelligence quotient (IQ) test scores when compared with their peers with normal hearing, even when both groups got results within normal limits.

In study 5 , in the overall score, children with UHL showed better scores on the expressive language tests when compared with children with bilateral hearing loss. However, the results were lower when the children with UHL were compared with children with normal hearing. Among the group of children with UHL, those who had sensorineural hearing loss presented better scores on the tests that assessed expressive language as well as other auditory skills, when compared with children with conductive UHL.

In study 4, children with UHL achieved better scores on the cognitive tests than those with bilateral hearing loss. On the receptive language test, children with continuous UHL 
Table 3 Number of participants in the studies and type and degree of hearing loss, according to the analysis of selected articles

\begin{tabular}{|c|c|c|c|}
\hline Study & $\begin{array}{l}\text { Total sample size/ } \\
\text { children with UHL }\end{array}$ & Type of loss in children with UHL & Degree of loss in children with UHL \\
\hline $1^{10}$ & $148 / 74$ & NR & $\begin{array}{l}4 \text { children with mild } \mathrm{HL} \text {; } \\
15 \text { children with moderate } \mathrm{HL} \text {; } \\
11 \text { children with severe } \mathrm{HL} \text {; } \\
44 \text { children with profound HL }\end{array}$ \\
\hline $2^{20}$ & $81 / 21$ & Sensorineural & Severe and profound \\
\hline $3^{18}$ & $57 / 8$ & Conductive & NR \\
\hline $4^{21}$ & $429 / N R$ & Conductive & Mild and moderate \\
\hline $5^{22}$ & $286 / 55$ & Conductive or sensorineural & NR \\
\hline
\end{tabular}

Abbreviations: $\mathrm{HL}$, hearing loss; NR, not reported.

Table 4 Tests used for language assessment and cognitive aspects, according to the analysis of selected articles

\begin{tabular}{|c|c|c|c|}
\hline Study & Receptive language & Expressive language & Others \\
\hline $1^{10}$ & Scale listening comprehension & Scale oral expression & $\begin{array}{l}\text { Wechsler Abbreviated Scale of } \\
\text { Intelligence }\end{array}$ \\
\hline $2^{20}$ & Verbal reasoning ${ }^{4}$ & Verbal reasoning ${ }^{4}$ & $\begin{array}{l}\text { Abstract visual reasoning }{ }^{\mathrm{a}} ; \\
\text { numeric reasoning } \\
\text { memory }^{\mathrm{a}} \text {; short-term }\end{array}$ \\
\hline $3^{18}$ & NR & NR & $\begin{array}{l}\text { Swedish phonemically balanced; } \\
\text { Swedish phonemically balanced } \\
\text { words in noise }\end{array}$ \\
\hline $4^{21}$ & $\begin{array}{l}\text { Peabody Picture } \\
\text { Vocabulary Test: Revised }\end{array}$ & $\begin{array}{l}\text { Number of different words; spon- } \\
\text { taneous speech sample; mean } \\
\text { length of utterance in morphemes; } \\
\text { percentage of consonants correct: } \\
\text { revised }\end{array}$ & $\begin{array}{l}\text { McCarthy Scales of Children's } \\
\text { Abilities, including general cogni- } \\
\text { tive index; verbal, perceptual per- } \\
\text { formance, and quantitative } \\
\text { subscales; }\end{array}$ \\
\hline $5^{22}$ & NR & $\begin{array}{l}\text { Speech motor function; phoneme } \\
\text { mobilization; phonology }\end{array}$ & $\begin{array}{l}\text { Speech in noise; phoneme dis- } \\
\text { crimination; emotional prosody; } \\
\text { language memory; mental } \\
\text { development }\end{array}$ \\
\hline
\end{tabular}

Abbreviation: NR, not reported.

${ }^{\text {a }}$ Subtests from Stanford-Binet Intelligence Scale of the Terman and Merrill (4th edition, short version).

achieved lower scores compared with children with bilateral hearing loss (continuous or intermittent). Regarding expressive language, the group with UHL achieved lower scores on the vocabulary test compared with the children with bilateral hearing loss. Even with lower scores, there was no statistically significant difference between the groups with unilateral and bilateral hearing loss.

With regard to studies conducted exclusively with children with UHL, study 3 showed that the normal ear tested for speech perception in silence and with background noise achieved scores close to $100 \%$, which is considered normal. The ear that presented hearing problems, however, showed scores that were lower than expected.

\section{Discussion}

Since 1980, studies have raised questions related to UHL and its implications on people's lives. ${ }^{3,4}$ According to the present study, no consensus was found on the impact on language acquisition and development in children with UHL.
It has been observed, through a bibliographical survey, that few studies have focused on possible language disorders and, when the issue was approached, it was because this population was part of heterogeneous groups, which also showed bilateral hearing loss, among other problems.

Among the studies that have specifically evaluated the language of children with UHL, a great variety of tests were observed, which demonstrates that there is no standardization for the evaluation of children with this type of hearing loss.

According to the articles included in this study, it was verified that the tests used to evaluate language did not meet the protocol requirements for the evaluation of this skill in children with UHL, but rather they were designed to evaluate children with other types of language disorders.

It is possible to observe that there was no standardization of language tests for populations of children with either unilateral or bilateral hearing loss. Moreover, the scores obtained by children with UHL have been compared with the tests' standardization, that is, the comparison was 
performed with a sample of children without language disorders in relation to age. However, the difficulties presented by children with UHL should go through qualitative evaluations, because the results of the selected studies ${ }^{10,11,18,20,21}$ evidenced that there were impacts on difficulties in their language, but they did not report in which formal and nonformal language levels (phonetic, phonological, syntactic, semantic, or pragmatic) such difficulties were present.

Concerning the application of the tests, it was found that children with UHL demonstrated lower scores on both receptive and expressive language tests when compared with their peers with normal hearing. ${ }^{10,20}$ When the performance of children with minimal hearing loss was checked, ${ }^{22}$ those with UHL obtained better scores on the expressive language tests than the children with mild bilateral degrees of hearing loss, high-frequency hearing loss, or conductive hearing loss. Only in one study ${ }^{21}$ did the children with UHL achieve lower scores than the ones with mild or moderate bilateral hearing loss on the receptive and expressive language tests. However, the differences were not significant between the two groups.

In the cognitive tests, it was observed that children with UHL had similar scores as children with normal hearing. ${ }^{10,20}$ When compared with the group of children with minimal hearing loss, children with UHL achieved better scores. ${ }^{21,22}$

Another study ${ }^{23}$ reported that vocabulary development in children involves learning meanings and names of the different objects common to their daily lives, which requires an integration of perceptual information. It can be assumed that if there is a need for integration of perceptual information for proper language acquisition and development, even minimal hearing loss can interfere with this process.

Not all children with UHL will develop learning or communication disabilities, but early identification of hearing loss is a factor that will contribute to greater attention to the follow-up of language development and, later on, the school performance of these children. The use of hearing aids, FM systems, and preferential classroom seating can help these children improve their school performance. However, this measure alone might not be able to counter learning disabilities or even assure whether the problems created in childhood may persist into adulthood. ${ }^{4}$

With regard to the characterization of hearing loss, five of the surveyed studies ${ }^{10,18,20-22}$ indicated the type of hearing loss, and three $10,20,21$ indicated the degree of hearing loss. Concerning the use of hearing aid devices, four studies $^{10,18,21,22}$ revealed their use, however, one ${ }^{18}$ did not specify whether they were used in children. These data demonstrate a large bias in their interpretation, because the participants were not evenly divided, mainly according to the degree of hearing loss and intervention used, as more severe hearing loss with late intervention might demonstrate greater impairment in the ability to identify the acoustic characteristics of speech sounds ${ }^{24}$ causing a negative impact on language development. The studies ${ }^{10,18,21,22}$ did not report the effectiveness of these devices-in other words, the time of daily use and the situations in which they were used.

In the articles analyzed, ${ }^{18,22}$ the main difficulties that children with UHL presented were sound localization and speech recognition in background noise. The speech recognition skill showed discrepancies not only in background noise but also in silence, as demonstrated in one of the studies. ${ }^{22}$ Concerning sound localization difficulties, if it is present in children with UHL, it can make the child waste more time trying to locate the speaker in the environment, thus having reduced attentional and visual cues, and may miss some of the intended communicative messages. ${ }^{2}$

In a comparative study ${ }^{25}$ with 25 children with UHL and their peers with normal hearing, it was concluded that children with UHL achieved lower scores in sound localization tasks when compared with normal-hearing children and that such problems increased proportionally to the hearing loss severity. Speech recognition was also compromised in these children, both in silence and in noise, regardless of the ear in which the stimulus and noise were addressed.

\section{Final Comments}

There are still many questions about UHL, probably because this type of hearing loss causes little damage to those who have it, compared with bilateral hearing loss. It is possible that impairments in other nonauditory functions will arise due to this loss and consequently interfere with the quality of life of this population.

Few studies were found using language tests in children with UHL or describing language disorders that occur as a result. Further prospective studies associating language disorders in children with UHL will be required to establish which language difficulties can be seen in children with UHL.

Parameters have not been established for the impact on the development of language in children with UHL, and it is expected that longitudinal studies with standardized tests are conducted on large samples of children to highlight the consequences of this type of sensory deprivation in the language.

\section{Note}

Study performed in the Speech-Language Pathology and Audiology Graduate Program (Master's Degree), Bauru School of Dentistry, Universidade de São Paulo-USPBauru (SP), Brazil.

\section{References}

1 Lü J, Huang Z, Yang T, et al. Screening for delayed-onset hearing loss in preschool children who previously passed the newborn hearing screening. Int J Pediatr Otorhinolaryngol 2011;75(8): 1045-1049

2 McKay S, Gravel JS, Tharpe AM. Amplification considerations for children with minimal or mild bilateral hearing loss and unilateral hearing loss. Trends Amplif 2008;12(1):43-54

3 Bess FH, Tharpe AM. Unilateral hearing impairment in children. Pediatrics 1984;74(2):206-216

4 Tharpe AM. Unilateral and mild bilateral hearing loss in children: past and current perspectives. Trends Amplif 2008;12(1): 7-15 
5 Gelfand SA, Silman S. Apparent auditory deprivation in children: implications of monaural versus binaural amplification. J Am Acad Audiol 1993;4(5):313-318

6 Hattori H. Ear dominance for nonsense-syllable recognition ability in sensorineural hearing-impaired children: monaural versus binaural amplification. J Am Acad Audiol 1993;4(5):319-330

7 Silman S, Gelfand SA, Silverman CA. Late-onset auditory deprivation: effects of monaural versus binaural hearing aids. J Acoust Soc Am 1984;76(5):1357-1362

8 Bess FH, Dodd-Murphy J, Parker RA. Children with minimal sensorineural hearing loss: prevalence, educational performance, and functional status. Ear Hear 1998;19(5):339-354

9 Tharpe AM, Bess FH. Identification and management of children with minimal hearing loss. Int J Pediatr Otorhinolaryngol 1991; 21(1):41-50

10 Lieu JEC, Tye-Murray N, Karzon RK, Piccirillo JF. Unilateral hearing loss is associated with worse speech-language scores in children. Pediatrics 2010;125(6):e1348-e1355

11 Balbani APS, Montovani JC. Impacto das otites médias na aquisição da linguagem em crianças. J Pediatr 2003;79(5):391-396

12 Lieu JEC. Speech-language and educational consequences of unilateral hearing loss in children. Arch Otolaryngol Head Neck Surg 2004;130(5):524-530

13 Yoshinaga-Itano C, Johnson CD, Carpenter K, Brown AS. Outcomes of children with mild bilateral hearing loss and unilateral hearing loss. Semin Hear 2008;29(2):196-211

14 Almeida K, Santos TMM. Seleção e adaptação de próteses auditivas em crianças. In: Almeida K, Iorio MCM, eds. Próteses auditivas: fundamentos teóricos e aplicações clínicas. São Paulo, SP, Brasil: Editora Lovise; 2003:357-380

15 Snik A, Leijendeckers J, Hol M, Mylanus E, Cremers C. The boneanchored hearing aid for children: recent developments. Int J Audiol 2008;47(9):554-559

16 Johnson JL, White KR, Widen JE, et al. A multicenter evaluation of how many infants with permanent hearing loss pass a two-stage otoacoustic emissions/automated auditory brainstem response newborn hearing screening protocol. Pediatrics 2005;116(3): 663-672

17 Santos MFC, Ziliotto KN, Monteiro VG, Hirata CHW, Pereira LD, Weckx LLM. Avaliação do processamento auditivo central em crianças com e sem antecedentes de otite média. Rev Bras Otorrinolaringol (Engl Ed) 2001;67(4):448-454

18 Priwin C, Jönsson R, Magnusson L, Hultcrantz M, Granström G. Audiological evaluation and self-assessed hearing problems in subjects with single-sided congenital external ear malformations and associated conductive hearing loss. Int J Audiol 2007;46(4): 162-171

19 Schmithorst VJ, Holland SK, Ret J, Duggins A, Arjmand E, Greinwald $\mathrm{J}$. Cortical reorganization in children with unilateral sensorineural hearing loss. Neuroreport 2005;16(5):463-467

20 Martínez-Cruz CF, Poblano A, Conde-Reyes MP. Cognitive performance of school children with unilateral sensorineural hearing loss. Arch Med Res 2009;40(5):374-379

21 Paradise JL, Feldman HM, Campbell TF, et al. Early versus delayed insertion of tympanostomy tubes for persistent otitis media: developmental outcomes at the age of three years in relation to prerandomization illness patterns and hearing levels. Pediatr Infect Dis J 2003;22(4):309-314

22 Borg E, Risberg A, McAllister B, et al. Language development in hearing-impaired children. Establishment of a reference material for a "Language test for hearing-impaired children," LATHIC. Int J Pediatr Otorhinolaryngol 2002;65(1):15-26

23 Jerger S, Lai L, Marchman VA. Picture naming by children with hearing loss: I. Effect of semantically related auditory distractors. J Am Acad Audiol 2002;13(9):463-477

24 Delgado-Pinheiro EMC, Antonio FL, Berti LC. Perfil audiológico e habilidades auditivas em crianças e adolescentes com perda auditiva. Estudos Linguísticos. 2010. [Accessed on: 2011 Dec 06]. Available at: http://www.gel.org.br/estudoslinguisticos/index.php 25 Bess FH, Tharpe AM, Gibler AM. Auditory performance of children with unilateral sensorineural hearing loss. Ear Hear 1986;7(1): $20-26$ 